\title{
Author Correction: Solar superstorm of AD 774 recorded subannually by Arctic tree rings
}

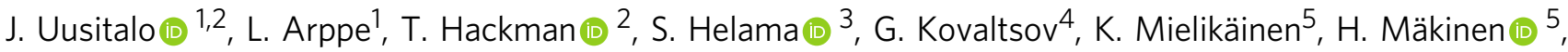 \\ P. Nöjd ${ }^{5}$, V. Palonen ${ }^{2}$, I. Usoskin 6 \& M. Oinonen (1) ${ }^{1}$
}

Correction to: Nature Communications (2019); https://doi.org/10.1038/s41467-018-05883-1; published online 28 August 2018

The authors became aware of a mistake in the data displayed in Fig. 1 and Supplementary Table 2 of the original version of the Article. Specifically, the ${ }^{14} \mathrm{C}$ production values were printed out in the code before the conversion between the omnidirectional fluence and the flux. As a consequence, the values of the ${ }^{14} \mathrm{C}$ production in Fig. 1 and Supplementary Table 2 were too high by a factor of $4 \times \pi=12.566$.

As a result of this, the following changes have been made to the originally published version of this Article:

In the original version of Fig. 1, the labels on the colour scale bar were incorrect. The previous incorrect version read, from top to bottom ' $1.40 \mathrm{E}+03,3.25 \mathrm{E}+03,8.00 \mathrm{E}+03,2.70 \mathrm{E}+04,6.00 \mathrm{E}+04,1.50 \mathrm{E}+05,1.75 \mathrm{E}+06,8.50 \mathrm{E}+06,5.25 \mathrm{E}+07,1.80 \mathrm{E}+08$, $2.29 \mathrm{E}+08$ '. The corrected figure replaces these with, from top to bottom ' $1.11 \mathrm{E}+02,2.59 \mathrm{E}+02,6.37 \mathrm{E}+02,2.15 \mathrm{E}+03,4.77 \mathrm{E}+03$, $1.19 \mathrm{E}+04,1.39 \mathrm{E}+05,6.76 \mathrm{E}+05,4.18 \mathrm{E}+06,1.43 \mathrm{E}+07,1.82 \mathrm{E}+07$ '

In the original version of Supplementary Table 2, the values in the second column were incorrect. The correct version of Supplementary Table 2 is:

\begin{tabular}{ll}
\hline $\boldsymbol{R}_{\boldsymbol{C}}(\mathbf{G V})$ & ${ }^{\mathbf{1 4}} \mathbf{C}$ production $\left(\right.$ atoms $\left./ \mathbf{c m}^{\mathbf{2}}\right)$ \\
\hline 0 & $1.82 \mathrm{E}+07$ \\
0.2 & $1.82 \mathrm{E}+07$ \\
0.7 & $1.43 \mathrm{E}+07$ \\
1.4 & $4.18 \mathrm{E}+06$ \\
2.4 & $6.76 \mathrm{E}+05$ \\
3.5 & $1.39 \mathrm{E}+05$ \\
6.1 & $1.19 \mathrm{E}+04$ \\
7.5 & $4.77 \mathrm{E}+03$ \\
8.9 & $2.15 \mathrm{E}+03$ \\
11.7 & $6.37 \mathrm{E}+02$ \\
14.1 & $2.59 \mathrm{E}+02$ \\
17.0 & $1.11 \mathrm{E}+02$ \\
\hline
\end{tabular}

which replaces the previous incorrect version:

\begin{tabular}{ll}
\hline $\boldsymbol{R}_{\mathbf{C}}(\mathbf{G V})$ & ${ }^{\mathbf{1 4}} \mathbf{C}$ production (atoms $\left./ \mathbf{c m}^{\mathbf{2}}\right)$ \\
\hline 0 & $2.29 \mathrm{E}+08$ \\
0.2 & $2.29 \mathrm{E}+08$ \\
0.7 & $1.80 \mathrm{E}+08$ \\
1.4 & $5.25 \mathrm{E}+07$ \\
2.4 & $8.50 \mathrm{E}+06$ \\
3.5 & $1.75 \mathrm{E}+06$ \\
6.1 & $1.50 \mathrm{E}+05$ \\
7.5 & $6.00 \mathrm{E}+04$ \\
8.9 & $2.70 \mathrm{E}+04$ \\
11.7 & $8.00 \mathrm{E}+03$ \\
14.1 & $3.25 \mathrm{E}+03$ \\
17.0 & $1.40 \mathrm{E}+03$ \\
\hline
\end{tabular}

\footnotetext{
${ }^{1}$ Finnish Museum of Natural History, University of Helsinki, P.O. Box 64, 00014 Helsinki, Finland. ${ }^{2}$ Department of Physics, University of Helsinki, P.O. Box 64, 00014 Helsinki, Finland. ${ }^{3}$ Natural Resources Institute Finland, Eteläranta 55, 96300 Rovaniemi, Finland. ${ }^{4}$ Ioffe Physical-Technical Institute,

Politekhnicheskaya 26, 194021 St. Petersburg, Russia. ${ }^{5}$ Natural Resources Institute Finland, Tietotie 2, 02150 Espoo, Finland. ${ }^{6}$ Space Climate Research Unit and Sodankylä Geophysical Observatory, University of Oulu, Pentti Kaiteran katu 1, 90014 Oulu, Finland. Correspondence and requests for materials should be addressed to J.U. (email: joonas.uusitalo@helsinki.fi)
} 
This has been corrected in both the PDF and HTML versions of the Article. This error does not affect the main result, original discussion or conclusions of the Article.

Published online: 15 March 2019

(c) Open Access This article is licensed under a Creative Commons Attribution 4.0 International License, which permits use, sharing, adaptation, distribution and cc reproduction in any medium or format, as long as you give appropriate credit to the original author(s) and the source, provide a link to the Creative Commons license, and indicate if changes were made. The images or other third party material in this article are included in the article's Creative Commons license, unless indicated otherwise in a credit line to the material. If material is not included in the article's Creative Commons license and your intended use is not permitted by statutory regulation or exceeds the permitted use, you will need to obtain permission directly from the copyright holder. To view a copy of this license, visit http://creativecommons.org/licenses/by/4.0/.

(C) The Author(s) 2019 